Keisuke Shioji · Junko Nishioka · Hiroaki Naraba

Yoshihiro Kokubo · Toshifumi Mannami

Nozomu Inamoto $\cdot$ Kei Kamide $\cdot$ Shin Takiuchi

Masayoshi Yoshii · Yoshikazu Miwa · Yuhei Kawano

Toshiyuki Miyata $\cdot$ Shunichi Miyazaki $\cdot$ Yoichi Goto

Hiroshi Nonogi · Naomi Tago · Naoharu Iwai

\title{
A promoter variant of the ATP-binding cassette transporter A1 gene alters the HDL cholesterol level in the general Japanese population
}

Received: 21 November 2003/ Accepted: 24 December 2003/Published online: 21 February 2004

(C) The Japan Society of Human Genetics and Springer-Verlag 2004

\begin{abstract}
To investigate the effects of polymorphisms in the ATP-binding cassette transporter A1 (ABCA1) gene on the high-density lipoprotein cholesterol (HDL-C) level and the incidence of myocardial infarction (MI), we performed association studies. Sequence analysis identified 14 polymorphisms in the promoter region of $A B C A 1$. After considering linkage disequilibrium, three polymorphisms in the promoter region and 11 polymorphisms from the JSNP database were determined in 1,880 subjects recruited from the Suita Study, representing the general population in Japan. We evaluated the association between the $A B C A 1$ genotype and HDL-C level adjusted not only for standard factors, but also for genetic factors including ApoA1 and ApoE genotypes. Of the 14 polymorphisms tested, the $G(-273) \mathrm{C}(P=0.0074), C(-297) \mathrm{T}$ $(P=0.0195)$, and $I M S-J S T 071749(P=0.0093)$ polymorphisms were significantly associated with the HDL-C level in the Suita population. We could reconfirm that the
\end{abstract}

K. Shioji $\cdot$ J. Nishioka $\cdot$ H. Naraba $\cdot$ N. Tago $\cdot$ N. Iwai $(\bowtie)$

Department of Epidemiology, Research Institute,

National Cardiovascular Center,

5-7-1 Fujishirodai, Suita,

Osaka 565-8565, Japan

E-mail: niwai@res.ncvc.go.jp

Tel.: + 81-6-68335012

Fax: + 81-6-68352088

Y. Kokubo · T. Mannami $\cdot$ N. Inamoto $\cdot$ T. Miyata

Department of Preventive Cardiology,

National Cardiovascular Center,

5-7-1 Fujishirodai, Suita,

Osaka 565-8565, Japan

K. Kamide $\cdot$ S. Takiuchi $\cdot$ M. Yoshii $\cdot$ Y. Miwa $\cdot$ Y. Kawano Division of Hypertension and Nephrology,

National Cardiovascular Center,

5-7-1 Fujishirodai, Suita,

Osaka 565-8565, Japan

S. Miyazaki $\cdot$ Y. Goto $\cdot$ H. Nonogi

Division of Cardiology,

National Cardiovascular Center, 5-7-1 Fujishirodai,

Suita, Osaka 565-8565, Japan
$G(-273)$ C genotype was influential in another set of subjects $(P=0.0310, n=743)$. However, the distribution of the $A B C A 1 G(-273) C$ genotype in subjects with MI $(n=598)$ was not different from that in the control population $(n=801)$. These results indicate that $A B C A 1$ $G(-273) \mathrm{C}$ has a significant effect on the HDL-C level in the general Japanese population, but not on the incidence of MI.

Keywords ABCA1 - Polymorphism - Association study · HDL cholesterol · Myocardial infarction

\section{Introduction}

The high-density lipoprotein cholesterol (HDL-C) level is inversely correlated with the development of atherosclerosis and is inversely related to the incidence of coronary artery disease (Castelli et al. 1986) and ischemic stroke in the elderly (Sacco et al. 2001). The HDL-C level has been shown to be affected by both genetic and environmental factors, including obesity, smoking, and alcohol consumption. Among genetic factors, the apolipoprotein A1 (ApoAl) (Groenendijk et al. 2001a,b) and $A p o E$ genotypes (Lefevre et al. 1997; Katsuya et al. 2002) are well known to influence the HDL-C level.

Genetic mutations in the ATP-binding cassette transporter A1 (ABCAl) gene have been shown to cause Tangier disease (TD) (Bodzioch et al. 1999; BrooksWilson et al. 1999; Rust et al. 1999) and familial HDL deficiency (Marcil et al. 1999). ABCA1 regulates cellular cholesterol efflux and facilitates lipid binding to ApoA1 (Wang and Tall 2003). Patients with TD show characteristic HDL deficiency, defective apolipoprotein-mediated phospholipid and cholesterol efflux from cells, and the accumulation of macrophage foam cells in various tissues, including arteries (Clifton-Bligh et al. 1972). Recent epidemiological studies have reported that $A B C A 1$ polymorphisms were associated with the HDL-C level 


\begin{tabular}{|c|c|c|c|c|c|}
\hline-1600 & AAGGGGCCATGCCACCCAGA & GTTATGAGTACCTGGGACTC & CAGAATTCCTTGCCTGGTGG & $\begin{array}{l}\text { CCTCCACATGCACTTCCAGG } \\
\end{array}$ & $\begin{array}{l}\text { GCCTGCTTGGGCCTCTTCTA } \\
\end{array}$ \\
\hline-1500 & $\begin{array}{l}\text { TGGGTCTGTCCTGAGTGTTG } \\
\text { G(-1498)C }\end{array}$ & ATAGAACCACTGATGTGAGT & ACCTGGGCTTGAGCCGTGGC & $\begin{array}{l}\text { CTGGAGATCCTGTTGACTGT } \\
\text { T(-1423)C }\end{array}$ & AGCATGGAGGGGGCTTGTGC \\
\hline-1400 & $\begin{array}{r}\text { AGCTGAATGTCTGIATGCAG } \\
\text { T(-1387)C }\end{array}$ & GTGGTGGGAGTTCTGGAATA & TGATGGAGCTGGAGGTGGGA & AGAGAAGTAGGCTTGGGGCA & GСTCTCTCATGCCACCTCAT \\
\hline-1300 & TCTGGCCAAAACTCAGGTCA & AACTGTGAAGAGTCTAAATG & TGAATCTGCCCTTCAAGGTG & GCTACAAAGGTATCTTTGTC & AAGGTAGGAGACCTTGTGGC \\
\hline-1200 & CTCCACGTGCACTTCCAGGG & СCTGCTTGGGCCTCTTCTAC & GGGTCTGTCCTGAGTCTTCT & ATGAATCTGCCCTTCAGGGC & AGATTCATATTTAGACTCTT \\
\hline-1100 & CACAGTTTGACCTGAGTTTT & GGCCAGAATAAGGTGACATT & TAGTTTGTTGGCTTGATGGA & TGACTTAAATATTTAGACAT & $\begin{array}{l}\text { ATGGTGTGTAGGCCTGCATT } \\
\text { AT(-1019)(-) }\end{array}$ \\
\hline-1000 & $\begin{array}{l}\text { CСTACTCTTGCCTTTTTTTT } \\
(-980) \mathrm{T}(10) / \mathrm{T}(9) / \mathrm{T}(8)\end{array}$ & TGCCCCTCCAGTGTTTTGGG & TAGTTTTGCTCCCCTACAGC & $\begin{array}{r}\text { CAAAGGCAAACAGATAAGTT } \\
\text { G(-926)T }\end{array}$ & GGAGGTCTGGAGTGGCTACA \\
\hline-900 & TAATTTTACACGACTGCAAT & TCTCTGGCTGCACTTCACAA & ATGTATACAAACTAAATACA & AGTCCTGTGTTTTTATCACA & GGGAGGCTGATCAATATAAT \\
\hline-800 & $\begin{array}{c}\text { GAAATTAAAAGGGGGCTGGT } \\
\text { G(-790)A }\end{array}$ & CCATATTGTTCTGTGTTTTT & $\begin{array}{l}\text { GTTTGTTT_GTTTCTTTTTTT } \\
\text { GTTTTGTTT(-752)(- )(I/D \#1) }\end{array}$ & GTTTTTGTGGCCTCCTTCCT & CTCAATTTATGAAGAGAAGC \\
\hline-700 & AGTAAGATGTTCCTCTCGGG & TCCTCTGAGGGACCTGGGGA & GCTCAGGCTGGGAATCTCCA & AGGCAGTAGGTCGCCTATCA & AAAATCAAAGTCCAGGTTTG \\
\hline-600 & TGGGGGGAAAACAAAAGCAG & CCCATTACCCAGAGGACTGT & $\begin{array}{l}\text { CСGCCTTCCCCTCACCCCAG } \\
\mathrm{C}(-559) \mathrm{T}\end{array}$ & CCTAGGCCTTTGAAAGGAAA & CAAAAGACAAGACAAAATGA \\
\hline-500 & TTGGCGTCCTGAGGGAGATT & CAGCCTAGAGCTCTCTCTCC & CCСAATCCCTCCCTCCGGCT & GAGGAAACTAACAAAGGAAA & $\begin{array}{l}\text { AAAAAATTGCGGAAAGCAGG } \\
\text { G(-402)C }\end{array}$ \\
\hline-400 & ATTTAGAGGAAGCAAATTCC & ACTGGTGCCCTTGGCTGCCG & GGAACGTGGACTAGAGAGTC & TGCGGCGCAGCCCCGAGCCC & AGCGCTTCCCGCGCGTCTTA \\
\hline-300 & $\begin{array}{l}\text { GGCCGGCGGGCCCGGGCGGG } \\
\text { C(-297)T }\end{array}$ & $\begin{array}{l}\text { GGAAGGGGACGCAGACCGCG } \\
\text { G(-273)C }\end{array}$ & GACCCTAAGACACCTGCTGT & $\begin{array}{c}\text { ACCCTCCACCCCCA_CCCCAC } \\
\text { TGGGG(-226)(-) (I/D } \# 2)\end{array}$ & ССАССТССССССААСТСССТ \\
\hline-200 & AGATGTGTCGTGGGCGGCTG & AACGTCGCCCGTTTAAGGGG & CGGGCCCCGGCTCCACGTGC & TTTCTGCTGAGTGACTGAAC & TACATAAACAGAGGCCGGGA \\
\hline-100 & $\begin{array}{l}\text { ACGGGGCGGGGAGGAGGGAG } \\
\text { G(-99)C }\end{array}$ & AGCACAGGCTTTGACCGATA & GTAACCTCTGCGCTCGGTGC & AGCCGAATCTATAAAAGGAA & $\begin{array}{l}\text { CTAGTCCCGGCAAAAACCCC } \\
\text { C(-14)T }\end{array}$ \\
\hline 1 & GTAATTGCGAGCGAGAGTGA & GTGGGGCCGGGACCCGCAGA & $\begin{array}{c}\text { GCCGAGCCGAC } \frac{C}{C} C T T C T C T C \\
\text { C52A }\end{array}$ & $C C G G G C T G C G G C A G G G C A G G$ & GCGGGGAGCTCCGCGCACCA \\
\hline 101 & ACAGAGCCGGTTCTCAGGGC & GCTTTGCTCCTTGTTTTTTC & CCCGGTTCTGTTTTCTCCCC & TTCTCCGGAAGGCTTGTCAA & GGGGTAGGAGAAAGAGACGC \\
\hline 201 & AAACACAAAAGTGGAAAACA & GGTAAGAGGCTCTCCAGTGA & CTTACTTGGGCGTTATTGTT & TTGTTTCGAGGCCAAGGAGG & CTTCGGGAAGTGCTCGGTTT \\
\hline 301 & $\begin{array}{c}\text { CGGGGACTTTGATCCGGAGC } \\
\text { T313C }\end{array}$ & СССАСАТССССАССАСТTGC & AACTCAGATGGGACCGGAGG & $\begin{array}{l}\text { CGGTGTTAAATGGGGAGACG } \\
\text { G380T }\end{array}$ & ATGTCCTAGTACGAGCTCTG \\
\hline 401 & GTGACCCCAGGACTCTGCGC & TGCTGCGCTTGGGGCTTGCC & CGACGGTGGAGACCGGGGAG & CATCTCTGGGCGTGGAGACC & CGGGCGCAGTACCCCGGGCT \\
\hline
\end{tabular}

Fig. 1 Nucleotide sequence of the 5 -flanking region and exon 1 of $A B C A 1$. The nucleotide sequence in italics indicates exon 1

(Wang et al. 2000; Clee et al. 2001; Lutucuta et al. 2001; Harada et al. 2003). However, few of these findings have been replicated, and there are inconsistencies among previous association studies. Accordingly, the associations between $A B C A 1$ variants and HDL-C are still controversial (Singaraja et al. 2003). One possible reason for these differences may be that the sample sizes in these studies were relatively small and lacked statistical power. Thus, to evaluate the effect of polymorphisms in $A B C A 1$ on the HDL-C level, we conducted an association study using a large cohort (the Suita population, $n=1,880$ ), representing the general population in Japan.

\section{Materials and methods}

\section{Subjects}

The Suita population The selection criteria and design of the Suita Study have been described previously (Mannami et al. 1997; Shioji et al. 2004). The genotypes were determined in 1,880 consecutive subjects who visited the National Cardiovascular Center between April 2002 and February 2003 (867 male subjects, 1,013 female subjects).

The hypertension group The hypertension (HTN) group consisted of 743 Japanese subjects (422 men and 321 women), aged 18-91 years $[65.2 \pm 0.4($ mean \pm SEM $)]$, who were enrolled in the Division of Hypertension and Nephrology at the National Cardiovascular Center between May 2001 and April 2003.

The myocardial infarction group The selection criteria and design of the myocardial infarction (MI) group have been described

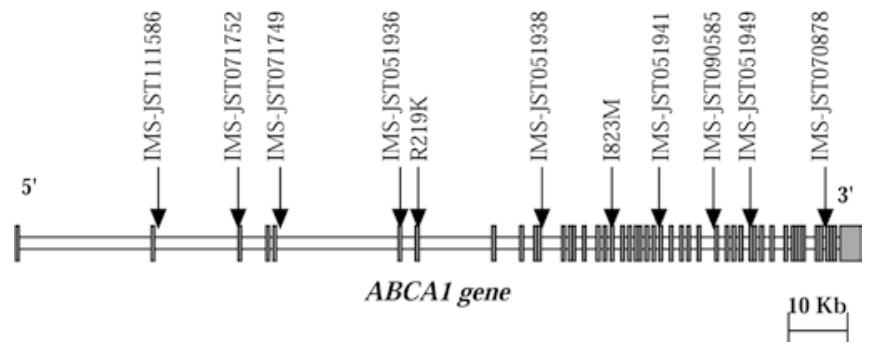

Fig. 2 Schema of $A B C A 1$ and the position of the determined polymorphisms.Grayboxes indicate exonic regions

previously (Takagi et al. 2002). This group consisted of 706 patients with MI (598 men and 108 women, aged $61.3 \pm 0.4$ years) who were enrolled in the Division of Cardiology at National Cardiovascular Center between May 2001 and April 2003. In the present study, we investigated only males $(n=598)$.

Written informed consent was obtained from every subject after a full explanation of the study, which was approved by the Ethics Committee of the National Cardiovascular Center and by the Committee on Genetic Analysis and Genetic Therapy of the National Cardiovascular Center.

\section{DNA studies}

The regions of the promoter and exon 1 in $A B C A 1$ were sequenced for polymorphisms in 24 subjects (Fig. 1). The primer sequences are available on request. For exonic regions (Fig. 2), we selected nine SNPs for genotyping from the public database (JSNP, http://snp.ims.u-tokyo.ac.jp) (Iida et al. 2001; Hirakawa et al. 2002). Well-known common variants, $A B C A 1$ R219K and I823M, were also selected (Wang et al. 2000; Clee et al. 2001; Harada et al. 2003).

The preliminary study revealed that JST-IMS005607 had the greatest effect on the HDL-C level among seven SNPs on the ApoAl region, including the promoter region (up to $-3 \mathrm{~Kb}$ ). 
Fig. 3A, B Residual HDL cholesterol levels among the $A B C A 1 G(-273) \mathrm{C}, C(-297) \mathrm{T}$, and $G(-790)$ Agenotypes. AResidual HDL cholesterol levels adjusted for sex, age, body-mass index, smoking, and alcohol consumption. B Residual HDL cholesterol levels adjusted for sex, age, body-mass index, smoking, alcohol consumption, ApoE genotype, and ApoAl genotype (JST-IMSO05603)
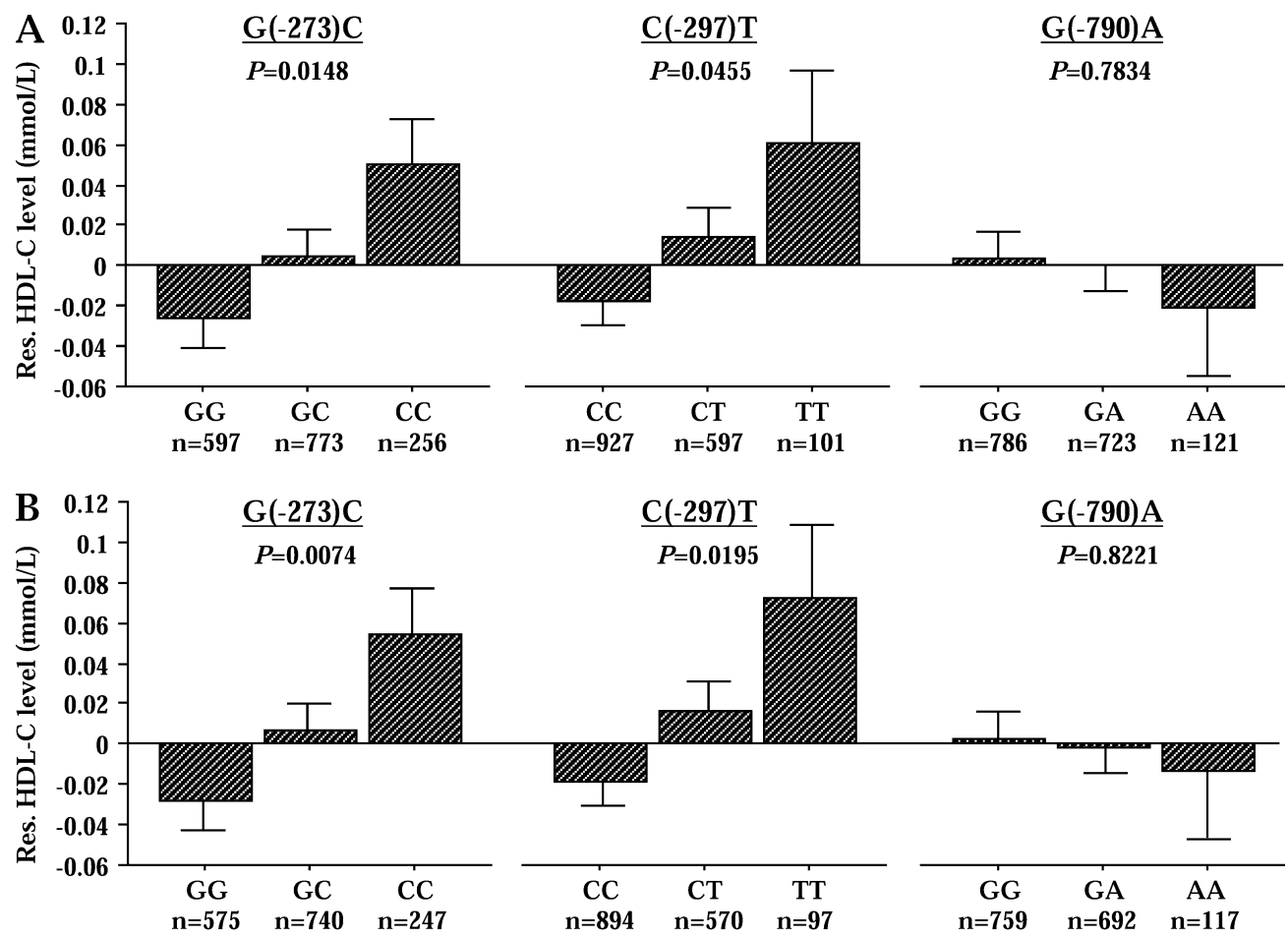

Thus, we selected JST-IMS005607 for adjusting HDL-C. The genotyping of $A p o E$ was performed according to a previous report (Katsuya et al. 2002). ApoE polymorphisms were categorized into three genotypes: $E 2(\epsilon 2 / \epsilon 2+\epsilon 2 / \epsilon 3+\epsilon 2 / \epsilon 4$ subjects), E3 ( $\epsilon 3 / \epsilon 3$ subjects), $E 4(\epsilon 3 / \epsilon 4+\epsilon 4 / \epsilon 4$ subjects) (Lefevre et al. 1997). All polymorphisms were determined by the TaqMan System.

\section{Statistical analysis}

Values are expressed as mean \pm standard error of the mean (SEM). For triglyceride values, a logarithmic transformation was applied for the statistical test, but untransformed values are shown in the Tables 1 and 2. All statistical analyses were performed with the JMP statistical package (SAS Institute). Values of $P<0.05$ were considered to indicate statistical significance. Multiple linear regression and multiple logistic analyses were performed with other covariates. The residual HDL-C level was calculated by adjusting for sex, age, and body-mass index (BMI), smoking (cigarettes/day) and consumption of alcohol (ethanol, $\mathrm{ml} /$ week). For analyses of the effects of the $A B C A 1$ genotype (in the Suita population), the residual HDL-C level was calculated by adjusting not only for the above five factors, but also for the ApoA1(JST-IMS005603), and the $A p o E(E 2, E 3$, and $E 4)$ genotypes. Differences in numerical data among the groups were evaluated by one-way analysis of variance (ANOVA). Hardy-Weinberg equilibrium was calculated by a chisquare test (Table 3). To measure linkage disequilibrium (LD) between SNPs, $D^{\prime}$ and $r^{2}$ values were analyzed using the SNPAlyze statistical package (Dynacom).

\section{Results}

Polymorphisms of the $5^{\prime}$-flanking region and exon 1 of the $A B C A 1$ gene

We found 14 polymorphisms in the promoter region, 1 polymorphism in exon 1 ( $5^{\prime}$-untranslated region), and 2 polymorphisms in intron 1 (Fig. 1).
LD was evaluated by calculating $r^{2}$ values (Table 1). We regarded $r^{2}>0.5$ as tight linkage. The minor allele frequency of the $T(-1423) C$ and $G 52 A$ polymorphisms was low (4\% each), and these SNPs were neglected in further analyses. The frequencies of $T(10), T(9)$, and $T(8)$ were 4,92 , and $4 \%$, respectively, in the $(-980) T(10) / T(9) / T(8)$ polymorphism, and this polymorphism was also neglected because this is not suitable for TaqMan genotyping. Accordingly, we selected three polymorphisms, $G(-790) \mathrm{A}, C(-297) \mathrm{T}$, and $G(-273) \mathrm{C}$, for the following association study.

\section{Association study of ApoAl and ApoE}

To observe the effect of $A B C A$ lpolymorphisms on the HDL-C level more clearly, the HDL-C level should be adjusted by various well-known influential factors.

The ApoAl IMS-JST005603 polymorphism was associated with the levels of HDL-C and triglyceride [HDL-C: TT $1.54 \pm 0.001 \mathrm{mmol} / 1$, TC $1.59 \pm 0.02$, CC $1.68 \pm 0.04, \quad P=0.0002$ (residual); triglyceride: TT $1.26 \pm 0.03 \mathrm{mmol} / 1, \quad$ TC $1.15 \pm 0.04, \quad$ CC $0.95 \pm 0.09$, $P<0.0001$ (residual)]. IMS-JST005603 corresponds to the HaeIII $(C 317 T)$ polymorphism described in a previous paper (Groenendijk et al. 2001b).

The ApoE polymorphism was also strongly associated with the levels of total cholesterol and HDL-C [total cholesterol: E2 $5.13 \pm 0.06 \mathrm{mmol} / 1, E 35.37 \pm 0.02$, E4 $5.41 \pm 0.05, \quad P=0.0002$ (residual); HDL-C: E2 $1 \mathrm{~s} .67 \pm 0.03 \mathrm{mmol} / 1, \quad$ E3 $1.56 \pm 0.01, \quad$ E4 $1.52 \pm 0.02$, $P<0.0001$ (residual)].

Accordingly, we evaluated the effect of the $A B C A 1$ polymorphisms on the HDL-C level adjusted for the 
Table 1 Linkage disequilibrium between SNPs in the $5^{\prime}$-flanking region and exon 1 of the $A B C A 1$ gene. I/D\#1 GTTTTGTTTT(-752)

\begin{tabular}{|c|c|c|c|c|c|c|c|c|}
\hline Genotype & $G(-1498) C$ & $T(-1423) C$ & $T(-1387) C$ & $A T(-1019)(-)$ & $G(-926) T$ & $G(-790) A$ & $\mathrm{I} / \mathrm{D} \# 1$ & $C(-559) T$ \\
\hline $\begin{array}{l}G(-1498) C \\
T(-1423) C \\
T(-1387) C \\
A T(-1019)(-) \\
G(-926) T \\
G(-790) A \\
\mathrm{I} / \mathrm{D} \# 1 \\
C(-559) T \\
G(-402) C \\
C(-297) T \\
G(-273) C \\
\mathrm{I} / \mathrm{D} \# 2 \\
G(-99) C \\
C(-14) T \\
C 52 A \\
T 313 C \\
G 380 T\end{array}$ & & 0.01976 & $\begin{array}{l}0.41818^{* * *} \\
0.04726\end{array}$ & $\begin{array}{l}\mathbf{1}^{* * *} \\
0.01976 \\
0.41818 * * *\end{array}$ & $\begin{array}{l}0.41818^{* * *} \\
0.04726 \\
\mathbf{1}^{* * *} \\
0.41818 * * *\end{array}$ & $\begin{array}{l}0.00047 \\
0.01003 \\
0.00111 \\
0.00047 \\
0.00111\end{array}$ & $\begin{array}{l}\mathbf{0 . 6 7 3 4 7} 7^{* * *} \\
0 \\
0.67347^{* * *} \\
0.67347^{* * *} \\
\mathbf{0 . 6 7 3 4 7} * * * \\
0.14667^{*}\end{array}$ & $\begin{array}{l}0.22034^{* *} \\
0.06087 \\
\mathbf{0 . 6 5 7 1 4} * * * \\
0.22034^{* *} \\
\mathbf{0 . 6 5 7 1 4} * * * \\
0.16483^{* * *} \\
\mathbf{1}^{* * *}\end{array}$ \\
\hline
\end{tabular}

$R^{2}$ values are shown in the upper right, and bolded values indicate $r^{2}>0.5$. Absolute $D^{\prime}$-values are shown in the lower left, and bolded Significance levels: ${ }^{*} P<0.05, * * P<0.01, * * * P<0.001$

ApoA1 IMS-JST005603 and ApoEpolymorphisms in addition to standard factors, including sex, age, BMI, smoking, and consumption of alcohol.

\section{Association study of $A B C A 1$ (Suita population)}

The association between the $G(-273)$ C polymorphism and the lipid level in the Suita population is presented in Table 2. The genotype frequency of the $G(-273) \mathrm{C}$ polymorphism in the Suita population was not deviated from the Hardy-Weinberg equilibrium. The HDL-C level adjusted for age, sex, BMI, smoking, and consumption of alcohol was significantly associated with the $G(-273) \mathrm{C}$ polymorphism $(P=0.0148)$. The $G(-273) \mathrm{C}$ polymorphism was even more tightly associated with the HDL-C level when adjusted for the ApoE and ApoAl(IMS$J S T 005603)$ genotypes in addition to the standard factors $(P=0.0074)$. The $C(-297) \mathrm{T}$ polymorphism was also associated with the HDL-C level $(P=0.0455$ adjusted for age, sex, BMI, smoking, and consumption of alcohol; $P=0.0195$ when also adjusted for the ApoE and ApoA1 genotypes). The effect of the $C(-297) \mathrm{T}$ polymorphism on the HDL-C level may be, at least in part, explained by its linkage with the $G(-273) \mathrm{C}$ polymorphism $\left(r^{2}=0.46667, D^{\prime}\right.$ value $\left.=1, P<0.0001\right) . G(-790)$ A was not associated with the lipid levels. Among the polymorphisms selected from JSNPs, including R219K and I823M, only the IMS-JST071749 polymorphism was associated with the HDL-C level $(P=0.0060$ adjusted for age, sex, BMI, smoking, and consumption of alcohol; $P=0.0093$ when also adjusted for the ApoE and ApoAI (IMS-JST005603) genotypes). The R219K and I823M polymorphisms were not associated with the HDL-C level $[P=0.3877 \quad(R 219 K)$ and $P=0.2286 \quad(I 823 M)$ adjusted for age, sex, BMI, smoking and consumption of alcohol; $P=0.1926(R 219 K)$ and $P=0.1209$ (I823M) when also adjusted for the $A p o E$ and ApoAl genotypes].
Association study of $A B C A 1$ (HTN group)

To reconfirm the association between the $G(-273) \mathrm{C}$, $C(-297) \mathrm{T}$, and IMS-JST071749 polymorphisms and the HDL-C level, we determined the genotypes in the HTN group. As shown in Table 3 , the $G(-273) \mathrm{C}$ polymorphism was associated with the residual HDL-C level $(P=0.0310)$. The genotype frequency of the $G(-273)$ C polymorphism in the HTN group was in accordance with Hardy-Weinberg equilibrium and did not differ from that of the Suita population $(P=0.2953)$. The $C(-297) \mathrm{T}(P=0.1829)$ and $I M S$ $J S T 071749(P=0.4130)$ polymorphisms were not associated with the residual HDL-C level. Thus, a positive association was observed between $G(-273) \mathrm{C}$ and the HDL-C level in two groups: the Suita population and the HTN group.

Association between $A B C A 1 G(-273) \mathrm{C}$ and incidence of MI

We next evaluated whether the ABCA1 G(-273)C polymorphism was associated with the incidence of MI. The HDL-C level in the male MI group $(1.09 \pm 0.01$, $P<0.0001)$ was significantly lower than that in the male Suita subjects $(1.44 \pm 0.02)$. The effects of this genotype on the HDL-C level were not observed in this group, probably because a substantial proportion of this group had dyslipidemia and had been treated with hypolipidemic drugs.

No significant association was observed between the $A B C A 1 G(-273) C$ polymorphism and the incidence of MI [the MI group: $G G \quad n=212(38.6 \%), G C \quad n=289$ $(45.2 \%), C C n=130(16.2 \%)$; the Suita population: $G G$ $n=309 \quad(35.5 \%), G C \quad n=362 \quad(48.3 \%), \quad C C \quad n=130$ $(16.2 \%), P=0.4443]$. 


\begin{tabular}{|c|c|c|c|c|c|c|c|c|}
\hline$G(-402) C$ & $C(-297) T$ & $G(-273) C$ & $\mathrm{I} / \mathrm{D} \# 2$ & $G(-99) C$ & $C(-14) T$ & C52A & $T 313 C$ & $G 380 T$ \\
\hline $0.22034 * *$ & $0.73333 * * *$ & $0.22034^{* *}$ & $0.73333 * * *$ & $0.29781^{* * *}$ & $0.55012 * * *$ & 0.01524 & $0.55012 * * *$ & $0.52781 * * *$ \\
\hline 0.06087 & 0.01449 & 0.06087 & 0.01449 & 0.06636 & $0.10559^{*}$ & $0.21726^{* * *}$ & $0.10559 *$ & $0.11538^{*}$ \\
\hline $0.22034 * *$ & $0.73333 * * *$ & $0.22034 * *$ & $0.73333 * * *$ & $0.29781 * * *$ & $0.55012 * * *$ & 0.01524 & $0.55012 * * *$ & $0.52781 * * *$ \\
\hline $0.65714^{* * *}$ & $0.30667 * * *$ & $0.65714 * * *$ & $0.30667 * * *$ & $0.71214 * * *$ & $0.37882 * * *$ & 0.04726 & $0.37882 * * *$ & $0.36111^{* * *}$ \\
\hline $0.16483 * *$ & 0.07692 & $0.16483^{* *}$ & 0.07692 & $0.15119^{* *}$ & $0.09502 *$ & 0.01003 & $0.09502 *$ & $0.09582 *$ \\
\hline $1 * * *$ & $1 * * *$ & $1 * * *$ & $1^{* * *}$ & $0.40741 * * *$ & $1 * * *$ & 0.06158 & $1 * * *$ & $1 * * *$ \\
\hline \multirow{6}{*}{$1 * * *$} & & $0.46667 * * *$ & $1 * * *$ & $0.21839^{* *}$ & $0.80952 * * *$ & 0 & $0.80952 * * *$ & $0.7978 * * *$ \\
\hline & & & $0.46667 * * *$ & $0.46798 * * *$ & $0.57647 * * *$ & 0.06087 & $0.57647 * * *$ & $0.55981 * * *$ \\
\hline & & & & $0.21839 * *$ & $0.80952 * * *$ & 0 & $0.80952 * * *$ & $0.7978 * * *$ \\
\hline & & & & & $0.26978 * * *$ & 0.06636 & $0.26978 * * *$ & $0.25325^{* * *}$ \\
\hline & & & & & & $0.10559 *$ & $1 * * *$ & $1 * * *$ \\
\hline & & & & & & & $0.10559 *$ & $\begin{array}{l}0.11538^{*} \\
\text { 1*** }\end{array}$ \\
\hline
\end{tabular}

values indicate $D^{\prime}>0.5$. All values refer to the variant allele indicated in the table

Table 2 Lipid levels in the $A B C A 1 G(-273) C$ genotypes (Suita population). Subjects who were receiving anti-hyperlipidemic medication were excluded. Values are mean \pm SEM. $P$-values calculated by ANOVA

\begin{tabular}{|c|c|c|c|c|}
\hline Factors & $G G$ & $G C$ & $C C$ & $P$-value \\
\hline$n$ (male/female) & $306 / 291$ & $358 / 415$ & $127 / 129$ & \\
\hline Age $(y)$ & $64.1 \pm 0.5$ & $63.7 \pm 0.4$ & $63.9 \pm 0.7$ & 0.7934 \\
\hline BMI $\left(\mathrm{kg} / \mathrm{m}^{2}\right)^{\mathrm{a}}$ & $22.7 \pm 0.1$ & $22.4 \pm 0.1$ & $22.9 \pm 0.2$ & 0.0607 \\
\hline Smoking (cigarettes/day) & $9.2 \pm 0.5$ & $8.5 \pm 0.5$ & $8.6 \pm 0.8$ & 0.5806 \\
\hline Alcohol consumption (ml/week) & $85.7 \pm 5.5$ & $80.1 \pm 4.9$ & $71.3 \pm 8.5$ & 0.3597 \\
\hline Total cholesterol $(\mathrm{mmol} / \mathrm{l})$ & $5.31 \pm 0.03$ & $5.36 \pm 0.03$ & $5.38 \pm 0.05$ & 0.3559 \\
\hline $\mathrm{HDL}^{\mathrm{b}}$ cholesterol $(\mathrm{mmol} / \mathrm{l})$ & $1.53 \pm 0.02$ & $1.58 \pm 0.01$ & $1.60 \pm 0.03$ & 0.0258 \\
\hline Triglycerides $(\mathrm{mmol} / \mathrm{l})^{\mathrm{c}}$ & $1.25 \pm 0.04$ & $1.15 \pm 0.03$ & $1.18 \pm 0.05$ & 0.2583 \\
\hline Residual HDL cholesterol $(\mathrm{mmol} / \mathrm{l})^{\mathrm{d}}$ & $-0.03 \pm 0.01$ & $0.00 \pm 0.01$ & $0.05 \pm 0.02$ & 0.0148 \\
\hline Residual HDL cholesterol $(\mathrm{mmol} / \mathrm{l})^{\mathrm{e}}$ & $-0.03 \pm 0.01$ & $0.01 \pm 0.01$ & $0.05 \pm 0.02$ & 0.0074 \\
\hline
\end{tabular}

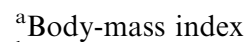

${ }^{\mathrm{b}}$ High-density lipoprotein

${ }^{\mathrm{c}}$ Test performed on log-transformed values

${ }^{\mathrm{d}}$ Residual HDL cholesterol was adjusted for sex, age, body-mass

index, smoking, and alcohol consumption
${ }^{\mathrm{e}}$ Residual HDL cholesterol was adjusted for sex, age, BMI, smoking, alcohol consumption, ApoEgenotype, and ApoAlgenotype (JST-IMSO05603)

Table 3 Lipid levels in the $A B C A 1 G(-273)$ Cgenotypes (hypertension group). Values are mean \pm SEM. $P$-values calculated by ANOVA

\begin{tabular}{|c|c|c|c|c|}
\hline Factors & $G G$ & $G C$ & $C C$ & $P$-value \\
\hline$n$ (male/female) & $165 / 128$ & $196 / 141$ & $58 / 47$ & \\
\hline Age $(y)$ & $64.5 \pm 0.6$ & $65.6 \pm 0.6$ & $65.3 \pm 1.1$ & 0.4561 \\
\hline BMI $\left(\mathrm{kg} / \mathrm{m}^{2}\right)$ & $24.1 \pm 0.3$ & $23.8 \pm 0.3$ & $23.3 \pm 0.4$ & 0.2766 \\
\hline Smoking (cigarettes/day) & $11.6 \pm 0.9$ & $10.9 \pm 0.9$ & $12.1 \pm 1.6$ & 0.7828 \\
\hline Drinking habit $(\mathrm{I} / \mathrm{II})^{\mathrm{a}}$ & $117 / 170$ & $154 / 180$ & $41 / 60$ & 0.3460 \\
\hline Total cholesterol (mmol/l) & $5.18 \pm 0.05$ & $5.28 \pm 0.05$ & $5.33 \pm 0.09$ & 0.2316 \\
\hline HDL cholesterol (mmol/l) & $1.31 \pm 0.02$ & $1.36 \pm 0.02$ & $1.44 \pm 0.04$ & 0.0259 \\
\hline Triglycerides $\left(\mathrm{mmol} / \mathrm{l}^{\mathrm{b}}\right.$ & $1.54 \pm 0.07$ & $1.52 \pm 0.07$ & $1.64 \pm 0.12$ & 0.9429 \\
\hline Residual HDL cholesterol $(\mathrm{mmol} / \mathrm{l})^{\mathrm{c}}$ & $-0.04 \pm 0.02$ & $0.02 \pm 0.02$ & $0.07 \pm 0.04$ & 0.0310 \\
\hline
\end{tabular}

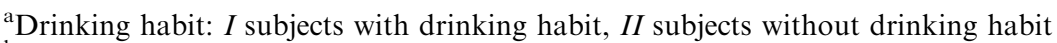

${ }^{\mathrm{b}}$ Test performed on log-transformed values

${ }^{c}$ Residual HDL cholesterol was adjusted for sex, age, BMI, smoking, and drinking habit

\section{Discussion}

In the present study, we evaluated the effects of polymorphisms in $A B C A 1$ on the HDL-C level using a large cohort representing the general population in Japan (the Suita Study). To evaluate the genetic influence of $A B C A$ lpolymorphisms on HDL-C level, the HDL-C level was adjusted not only for standard 
factors but also for other important genetic factors including the $A p o A l$ and $A p o E$ polymorphisms. Moreover, we reconfirmed the effects of $A B C A 1$ $G(-273)$ C polymorphism on HDL-C in the HTN group. We next investigated the association between the $A B C A 1 G(-273) C$ and the incidence of MI, but did not observe any association.

The present study is distinguished by three main features: (1) an association study using a large cohort study (the Suita population), (2) taking into account of the influence of the ApoA1 and ApoE polymorphisms, and (3) a confirmation of the association using another set of subjects (the HTN group).

We found that three SNPs were associated with the HDL-C level in 14 SNPs of the $A B C A$ lgene in the Suita population. However, if we applied Bonferroni's correction for multiple tests, three SNPs might not be considered significantly associated with the HDL-C level $[G(-273) \mathrm{C}, \quad P=0.1036: \quad C(-297) \mathrm{T}, \quad P=0.273$ : IMS-JST071749, $P=0.1302, P$ values are corrected by multiplying with 14 (14 SNPs)]. Thus, we verified this positive association in another set of subjects (the HTN group). This association study revealed that $G(-273)$ C, but not $C(-297) \mathrm{T}$ or IMS-JST071749, was associated with the HDL-C level. Thus, it is highly likely that $A B C A 1 G(-273) C$ was truly associated with the HDL-C level.

Since the $A B C A 1 G(-273) C$ polymorphism is in the promoter region, it is likely that this polymorphism may alter the expression level of ABCA1. However, this polymorphic site had no consensus sequence for transcriptional factors. The TGGGG(-226)(-) insertion-deletion polymorphism, which is one of the polymorphisms in LD with the $G(-273)$ C polymorphism $\left(r^{2}=0.46667\right)$, was in the middle of the consensus sequence of the ZNF202 binding site (GnT repeat)(Porsch-Ozcurumez et al. 2001). The insertion allele, which mainly corresponds to the $(-273) \mathrm{C}$ allele, should disrupt this binding site and may be associated with higher transcriptional activity of the $A B C A 1$ gene, which may lead to higher HDL cholesterol levels. However, the $C(-297)$ Tpolymorphism, which was in more tight LD with the TGGGG(-226)(-) insertion-deletion polymorphism, appeared to have less effect on the HDL cholesterol level than the $G(-273) \mathrm{C}$ polymorphism. It remains to be determined whether this discrepancy merely reflects a statistical error or if the $G(-273)$ C polymorphism might have additional functional significance. A more detailed promoter analysis will be needed to determine which polymorphisms are functionally important.

The present study revealed that the ABCA1I823M polymorphism was not associated with the HDL-C level, inconsistent with a previous report (Harada et al. 2003). This discrepancy may be due to the study design, since a small-scale association study has relatively weak statistical power. In the present study, the sample power was 0.77 for the distribution, sample size, frequencies of the alleles, and $\alpha$ value (0.05, two-tailed).
The sample size in the previous study $(n=410)$ does not seem to be sufficient to give adequate statistical power. Moreover, the frequency of the $I 823$ allele in the previous study (allele frequency 0.492 ) was different from that in the Suita population (0.36) and JSNP information (0.38). Thus, the subjects in the previous study did not seem to be representative of the general Japanese population, as noted by Harada et al. (2003).

Recently, the polymorphisms in the promoter region of $A B C A 1$, which corresponds to $C(-559) T$ in the present study and seems to be in tight linkage with $G(-273) \mathrm{C}\left(r^{2}=1, D^{\prime}\right.$-value $\left.=1\right)$, was found to be modestly, but not significantly $(P=0.09)$, associated with the HDL-C level using LCAS subjects (Lutucuta et al. 2001). The effect of the $A B C A 1 G(-273) C$ polymorphism on the HDL-C level was significant, but still relatively weak $\left(r^{2}=0.0050\right)$. Accordingly, the sample size $(n=372)$ in the previous study (Lutucuta et al. 2001) seems to have been too small to detect the effect of polymorphisms on the HDL-C level clearly.

While the $A B C A 1 G(-273) C$ polymorphism was associated with HDL-C level, it was not found to be associated with the incidence of MI. The ApoE polymorphism $(E 2, E 3$, and E4) had the greatest influence on the HDL-C level among the three polymorphisms, ABCAl $G(-273) \mathrm{C} \quad\left(r^{2}=0.0050\right), \quad$ ApoAl $J S T-I M S 005603$ (0.0100), and ApoE(0.0118). However, the $A p o E$ polymorphism was only weakly associated with the incidence of MI $(P=0.0840)$. Thus, $A B C A 1$ $G(-273)$ C may have too weak an influence on the HDL-C level to alter the incidence of MI through a reduction of the HDL-C level. More large numbers of MI subjects might be necessary to detect the influence of the $A B C A 1 G(-273) C$ polymorphism on MI incidence.

In summary, the present study provides the first evidence that the common $A B C A 1 G(-273) C$ polymorphism in the promoter region is significantly associated with the level of HDL cholesterol in the Japanese.

Acknowledgements This study was supported by the Program for the Promotion of Fundamental Studies in Health Science of the Organization for Pharmaceutical Safety and Research of Japan. We would also like to thank Dr. Otosaburo Hishikawa, Dr. Katsuyuki Kawanishi, and Mr. Shigeru Kobayashi for their continuous support of our population survey in Suita City. We also thank the members of the Satsuki-Junyukai. Finally, we express our gratitude to Dr. Soichiro Kitamura, President of the National Cardiovascular Center, and to Dr. Hitonobu Tomoike, Direktor General of the National Cardiovascular Center Hospital, for their support of our study.

\section{References}

Bodzioch M, Orso E, Klucken J, Langmann T, Bottcher A, Diederich W, Drobnik W, Barlage S, Buchler C, PorschOzcurumez M, Kaminski WE, Hahmann HW, Oette K, Rothe G, Aslanidis C, Lackner KJ, Schmitz G (1999) The gene encoding ATP-binding cassette transporter 1 is mutated in Tangier disease. Nat Genet 22:347-351

Brooks-Wilson A, Marcil M, Clee SM, Zhang LH, Roomp K, van Dam M, Yu L, et al (1999) Mutations in $A B C 1$ in Tangier 
disease and familial high-density lipoprotein deficiency. Nat Genet 22:336-345

Castelli WP, Garrison RJ, Wilson PW, Abbott RD, Kalousdian S, Kannel WB (1986) Incidence of coronary heart disease and lipoprotein cholesterol levels. The Framingham Study. JAMA $256: 2835-2838$

Clee SM, Zwinderman AH, Engert JC, Zwarts KY, Molhuizen HOF, Roomp K, Jukema JW, van Wijland M, van Dam M, Hudson TJ, Brooks-Wilson A, Genest J Jr, Kastelein JJ, Hayden MR (2001) Common genetic variation in $A B C A$ lis associated with altered lipoprotein levels and a modified risk for coronary artery disease. Circulation 103:1198-1205

Clifton-Bligh P, Nestel PJ, Whyte HM (1972) Tangier disease. Report of a case and studies of lipid metabolism. N Engl J Med 286:567-571

Groenendijk M, Cantor RM, de Bruin TW, Dallinga-Thie GM (2001a) The apoAI-CIII-AIV gene cluster. Atherosclerosis 157:1-11

Groenendijk M, Cantor RM, De Bruin TWA, Dallinga-Thie GM (2001b) New genetic variants in the apoA-I and apoC-III genes and familial combined hyperlipidemia. J Lipid Res 42:188-194

Harada T, Imai Y, Nojiri T, Morita H, Hayashi D, Maemura K, Fukino K, Kawanami D, Nishimura G, Tsushima K, Monzen K, Yamazaki T, Mitsuyama S, Shintani T, Watanabe N, Seto K, Sugiyama T, Nakamura F, Ohno M, Hirata Y, Yamazaki T, Nagai R (2003) A common Ile 823 Met variant of ATP-binding cassette transporter A1 gene $(A B C A 1)$ alters high-density lipoprotein cholesterol level in Japanese population. Atherosclerosis 169:105-112

Hirakawa M, Tanaka T, Hashimoto Y, Kuroda M, Takagi T, Nakamura Y (2002) JSNP: a database of common gene variations in the Japanese population. Nucl Acids Res 30:158-162

Iida A, Saito S, Sekine A, Kitamura Y, Kondo K, Mishima C, Osawa S, Harigae S, Nakamura Y (2001) High-density singlenucleotide polymorphism (SNP) map of the $150-\mathrm{kb}$ region corresponding to the human ATP-binding cassette transporter A1 (ABCA1) gene. J Hum Genet 46:522-528

Katsuya T, Baba S, Ishikawa K, Mannami T, Fu Y, Inamoto N, Asai T, Fukuda M, Higaki J, Ogata J, Ogihara T (2002) Epsilon 4 allele of apolipoprotein E gene associates with lower blood pressure in young Japanese subjects: the Suita Study. J Hypertens 20:2017-2021

Lefevre M, Ginsberg HN, Kris-Etherton PM, Elmer PJ, Stewart PW, Ershow A, Pearson TA, Roheim PS, Ramakrishnan R, Derr J, Gordon DJ, Reed R (1997) ApoE genotype does not predict lipid response to changes in dietary saturated fatty acids in a heterogeneous normolipidemic population. The DELTA Research Group. Dietary effects on lipoproteins and thrombogenic activity. Arterioscler Thromb Vasc Biol 17:29142923

Lutucuta S, Ballantyne CM, Elghannam H, Gotto AM Jr, Marian AJ (2001) Novel polymorphisms in promoter region of ATP binding cassette transporter gene and plasma lipids, severity, progression, and regression of coronary atherosclerosis and response to therapy. Circ Res 88:969-973

Mannami T, Konishi M, Baba S, Nishi N, Terao A (1997) Prevalence of asymptomatic carotid atherosclerotic lesions detected by high-resolution ultrasonography and its relation to cardiovascular risk factors in the general population of a Japanese city: the Suita Study. Stroke 28:518-525

Marcil M, Brooks-Wilson A, Clee SM, Roomp K, Zhang LH, Yu L, Collins JA, van Dam M, Molhuizen HO, Loubster O, Ouellette BF, Sensen CW, Fichter K, Mott S, Denis M, Boucher B, Pimstone S, Genest J Jr, Kastelein JJ, Hayden MR (1999) Mutations in the $A B C 1$ gene in familial HDL deficiency with defective cholesterol efflux. Lancet 354:1341-1346

Porsch-Ozcurumez M, Langmann T, Heimerl S, Borsukova H, Kaminski WE, Drobnik W, Horner C, Schumacher C, Schmitz $\mathrm{G}$ (2001) The Zinc finger protein 202 (ZNF202) is a transcriptional repressor of ATP-binding cassette transporter A1 (ABCA1) and $A B C G 1$ gene expression and a modulator of cellular lipid efflux. J Biol Chem 276:12427-12433

Rust S, Rosier M, Funke H, Real J, Amoura Z, Piette JC, Deleuze JF, Brewer HB, Duverger N, Denefle P, Assmann G (1999) Tangier disease is caused by mutations in the gene encoding ATP-binding cassette transporter 1. Nat Genet 22:352-355

Sacco RL, Benson RT, Kargman DE, Boden-Albala B, Tuck C, Lin IF, Cheng JF, Paik MC, Shea S, Berglund L (2001) Highdensity lipoprotein cholesterol and ischemic stroke in the elderly: the Northern Manhattan Stroke Study. JAMA 285:2729-2735

Shioji K, Kokubo Y, Mannami T, Inamoto N, Morisaki H, Mino Y, Tago N, Yasui N, Iwai N (2004) Association between hypertension and the $\alpha$-adducin, $\beta 1$-adrenoreceptor and $\mathrm{G}$ protein $\beta 3$ subunit genes in the Japanese population: the Suita Study. Hypertens Res (in press)

Singaraja RR, Brunham LR, Visscher H, Kastelein JJP, Hayden MR (2003) Efflux and atherosclerosis. The clinical and biochemical impact of variation in the $A B C A 1$ gene. Arterioscler Thromb Vasc Biol 23:1322-1332

Takagi S, Iwai N, Yamauchi R, Kojima S, Yasuno S, Baba T, Terashima M, Tsutsumi Y, Suzuki S, Morii I, Hanai S, Ono K, Baba S, Tomoike H, Kawamura A, Miyazaki S, Nonogi H, Goto Y (2002) Aldehyde dehydrogenase 2 gene is a risk factor for myocardial infarction in Japanese men. Hypertens Res 25:677-681

Wang N, Tall AR (2003) Regulation and mechanisms of ATPbinding cassette transporter A1-mediated cellular cholesterol efflux. Arterioscler Thromb Vasc Biol 23:1178-1184

Wang J, Burnett JR, Near S, Young K, Zinman B, Hanley AJ, Connelly PW, Harris SB, Hegele RA (2000) Common and rare $A B C A 1$ variants affecting plasma HDL cholesterol. Arterioscler Thromb Vasc Biol 20:1983-1989 